\title{
Impacto de políticas de vivienda en las estrategias de acceso al hábitat urbano en Córdoba, Argentina
}

\author{
Impact of housing production policies in urban-habitat access strategies in Cordoba, Argentina
}

Sara María Boccolini*

Recibido: 08 de agosto de 2017

Aceptado: 17 de noviembre de 2017

\section{Resumen}

Se analizó el impacto de las políticas de producción de vivienda social en las estrategias de acceso a la vivienda urbana en Córdoba, Argentina, entre 2001 y 2015, verificando que estas normativas fomentan procesos de contraurbanización, periurbanización, inquilinización, y el vaciamiento de áreas pericentrales e intermedias.

Se analizaron las políticas públicas de producción directa e indirecta (financiamiento) de vivienda urbana, sistematizando información obtenida en entrevistas a actores clave, datos censales, resultados de investigaciones indexadas locales y regionales en torno al tema, e informes realizados por instituciones públicas y privadas, para reconstruir el alcance de estas políticas para resolver el déficit habitacional, su disponibilidad para distintos grupos socioeconómicos y los patrones de territorialización que emergen de ellas. Los resultados se plantearon como aporte en la discusión actual acerca de la producción de hábitat urbano en áreas metropolitanas de Argentina y Latinoamérica.

Palabras clave: contraurbanización, inquilinización, políticas de vivienda, ProCreAr.

\begin{abstract}
We analyzed the public policies of urban housing production in Córdoba (Argentina) between 2005 and 2015. As a result, we verified the hypothesis that they structure emergent processes of access to the urban habitat of the city: counterurbanization, increase of tenants, and shrinking population in pericentral and intermediate urban areas.

We analyzed the public policies of direct and indirect (financing) urban housing production, by means of systematizing information obtained from key agents, census data, indexed publications, and information produced by public and private institutions. We reconstructed the scope of these policies to solve the housing deficit, its availability to different socioeconomic groups, and the patterns of territorialization that emerge from them. The results are presented as a contribution in the current discussion on the production of urban habitat in metropolitan areas of Argentina and Latin America.
\end{abstract}

Keywords: counterurbanization, housing policies, increase of tenants, ProCreAr.

* Filiación: Instituto de Investigación de la Vivienda y del Hábitat (IINVIHAB/CEUR CONICET), Facultad de Arquitectura Urbanismo y Diseño, Universidad Nacional de Córdova, Córdova, Argentina. Correo electrónico: saraboccolini@gmail.com

Cómo citar: Boccolini, S. M. (2017). Impacto de políticas de vivienda en las estrategias de acceso al hábitat urbano en Córdoba, Argentina. Revista de Urbanismo, 37, 1-18. https://doi.org/10.5354/0717-5051.2017.46198 


\section{Introducción}

Las estrategias de acceso a la vivienda son fundamentales para entender los procesos emergentes de territorialización de las ciudades.

En este trabajo se analiza el impacto de las normativas de producción de vivienda social -es decir, de producción subsidiada total o parcialmente por el Estado- en las estrategias de acceso a la vivienda urbana en Córdoba, Argentina, en el período 2001-2015.

Se entienden las estrategias de acceso a la vivienda como las tendencias que emergen como resultado de las operaciones de innumerables agentes particulares (en este caso, los nuevos hogares que surgen en un grupo social determinado), con el fin de acceder a una vivienda que se adecúe lo mejor posible a sus necesidades específicas, de acuerdo con los recursos (económicos, territoriales, sociales, etc.) disponibles.

En el contexto argentino, estas estrategias se han mantenido constantes desde finales del siglo XIX hasta comienzos del siglo XXI (Boccolini, 2017c). Sin embargo, en los últimos años emergen tendencias divergentes.

En primer lugar, en un sistema que tiende a la concentración de población en los mayores centros urbanos (la macrocefalia que caracteriza la estructura urbana de Argentina), cada vez más hogares deciden abandonar las principales ciudades y reubicarse en localidades medianas y pequeñas de las grandes áreas metropolitanas. Esta contraurbanización (Cardoso, 2013) es simultánea al vaciamiento poblacional en las áreas pericentrales e intermedias de las grandes ciudades (Peralta y Liborio, 2014).

En segundo lugar, en una sociedad tradicionalmente formada por hogares propietarios, la cantidad de hogares inquilinos aumenta constantemente (Gargantini, 2014).

Por último, aunque la producción de viviendas urbanas ha sido una pujante actividad económicofinanciera, favorecida tanto por el contexto productivo regional y local como por la legislación nacional y municipal (Boccolini, 2017b; Yujnovsky, 1984), y que la producción de vivienda subsidiada por el Estado ha aumentado sobre todo en los últimos 15 años (Barreto, 2012), el déficit de viviendas aumenta no solo cuantitativa, sino también cualitativamente, y ya no se limita a los hogares de menores recursos, sino que alcanza a sectores cada vez más amplios de la sociedad (Peralta, 2006).

Este déficit supera la mera obsolescencia material de la vivienda. Incluye también el hacinamiento, no solo en cuanto cantidad de personas por cuarto, sino también debido a factores entre los que se cuentan que nuevos hogares no acceden a una vivienda propia, permaneciendo en el hogar materno o paterno (Instituto Nacional de Estadísticas y Censos, INDEC, 2012); la inquilinización, al no existir una regulación importante del alquiler de viviendas como bien social; y la pérdida de calidad urbana, en los casos en que la contraurbanización es consecuencia de una expulsión a áreas periféricas o sectores segregados espacial y socioeconómicamente (Arriagada Luco, 2003).

Este trabajo se encuadra en un proyecto de investigación donde el escenario actual de producción y estrategias de acceso a la vivienda urbana se ha explicado como resultado -entre otros factores- de la articulación dialéctica del Estado como regulador y facilitador (a través de estructuras jurídicas y legislativas) (Boccolini, 2017b), los agentes productores del ámbito privado (Boccolini, 2017a) y los consumidores finales, es decir, personas que habitan la ciudad (Boccolini, 2017c). En esta instancia -y en correlación con los resultados obtenidos hasta ahora- el objetivo principal es estudiar el rol del Estado, no ya como regulador, sino como agente activo productor de hábitat.

Debido a su escala de producción y difusión, la producción de vivienda subsidiada por el Estado tiene la capacidad de influir definitivamente en las estrategias de acceso a la vivienda, por lo que es un factor de importancia para explicar las nuevas tendencias que emergen en los últimos años. La hipótesis de trabajo es que las políticas de vivienda social fomentan directamente las estrategias de acceso a la vivienda desarrolladas actualmente.

En una sociedad altamente urbanizada y concentrada en el territorio como la argentina, el estudio particular de las estrategias de acceso a la vivienda urbana se hace imprescindible. Además, en un territorio cuyo principal centro urbano -Buenos Aires- tiene una escala tal que impide cualquier tipo de generalización al resto del territorio, el estudio de las ciudades secundarias es clave para comprender críticamente las estrategias 
emergentes de acceso a la vivienda. Por lo tanto, se estudia la situación particular en Córdoba, por su importancia socioeconómica y productiva, y porque en esta ciudad la producción habitacional y los procesos de acceso a la vivienda urbana tienen una escala que la destaca entre otros centros urbanos similares, cuyo análisis ofrece, sin embargo, resultados generalizables a centros urbanos de similar importancia: la correlación entre políticas públicas y estos procesos urbanos puede ser verificada en las principales áreas urbanas de Argentina y la región, abriendo el camino para futuras investigaciones sobre este tema.

El impacto de la producción de vivienda por el Estado en Argentina ha sido analizado en profundidad por diversos autores, haciendo foco sobre todo en su escasa diversidad tipológico-constructiva, y la concentración de su producción en unos pocos agentes, consecuencia de la escala de producción necesaria para paliar el déficit habitacional existente (Coulomb, 2012; Cravino, 2017; Cuenya, 1992; Yujnovski, 1984). También se ha demostrado el impacto de la producción de vivienda social en la reproducción de la segregación residencial socioeconómica de los hogares con menos recursos que son destinatarios principales de este modelo, repitiendo la situación de casos paradigmáticos de América Latina como México (Esquivel Hernández, Pérez y Cervantes Borja, 2005), Chile (Rodríguez y Sugranyes, 2004) y Brasil (Rotnik et al., 2015).

Siguiendo esta línea, las investigaciones en Córdoba hacen foco en el impacto de la vivienda social en la calidad ambiental y urbana que proveen a los hogares beneficiarios, concentrándose en las viviendas producidas directamente por el Estado para la población de menores recursos (Arqueros Mejica, Gil y de Anso, Mendoza y Zapata; Capdevielle, 2014; Gargantini, 2014; Molinatti, 2013; Barrionuevo, Garbellotto y Pasquale, 2011; Tecco y Fernández, 2005), principalmente el programa de relocalización de asentamientos informales Mi Casa Mi Vida (Elorza, 2016; Marengo y Elorza, 2016; Monayar, 2011).

Sin embargo, el objetivo de esta investigación es un análisis crítico e integral de las políticas estatales de producción de vivienda urbana y su impacto en la ciudad y su área metropolitana. No solo se amplía el análisis a los instrumentos de producción indirecta, es decir, programas de financiamiento hipotecario cuyos beneficiarios son también hogares de clase media. En este trabajo se entiende que las políticas públicas de producción de vivienda son estructuradoras directas de los procesos de contraurbanización, vaciamiento e inquilinización desarrollados en Córdoba, y afectan no solo a los hogares que son beneficiarios directos de estas políticas, sino a la población y el territorio en su conjunto.

\section{Metodología de trabajo}

La investigación se desarrolla en dos líneas simultáneas y complementarias que se detallan a continuación.

En primer término, el análisis respecto de las políticas de vivienda y las estrategias de acceso a la vivienda. Esto se realizó mediante la revisión documental de investigaciones indexadas en torno a casos locales, nacionales y latinoamericanos, para reconstruir cualitativamente las premisas que han estructurado históricamente estas políticas, e identificar los objetivos y alcance cuantitativo de los programas llevados a cabo (específicamente en Córdoba), diferenciando las intervenciones del Estado municipal, provincial y nacional. También permite identificar las estrategias de acceso al hábitat que estructuran el desarrollo urbano de la ciudad tradicionalmente, así como las nuevas tendencias que emergen en disonancia o contradicción con ellas.

En segundo plano, se procesan datos de fuentes secundarias, suministrados por los Censos de Población del Instituto Nacional de Estadística y Censos (INDEC) y cuyos resultados para Córdoba fueron procesados por la Dirección de Estadística y Censos de la Provincia de Córdoba (DEyC). Esto permite reconstruir cuantitativamente el parque habitacional existente en Córdoba, con los indicadores utilizados por el INDEC en cuanto a cantidad de viviendas por habitante y por hogar, déficit cuantitativo y cualitativo (por calidad material de las viviendas, hacinamiento por cuarto o por vivienda), y régimen de tenencia de la vivienda. Se evalúan los datos de distintos cortes censales, para poner en relevancia tendencias o disrupciones, haciendo hincapié en el período 2001-2010.

Se evalúa, además, el crecimiento poblacional por barrios de la ciudad (demostrando decrecimiento 
poblacional) y en relación con otros centros del Área Metropolitana de la Ciudad de Buenos Aires, AMCBA (verificando contraurbanización).

Ambas líneas de trabajo se combinan en la etapa de análisis del impacto de las políticas de vivienda. Primero, analizando la territorialización de cada programa, donde sus premisas se combinan con datos del mercado de suelo urbano (reconstruido mediante relevamiento de la oferta disponible en el año 2015, entrevistas a actores clave, y datos del proyecto "Valores del suelo en América Latina" del Lincoln Institute, demostrando el impacto de las políticas de vivienda en la contraurbanización y vaciamiento de áreas pericentrales e intermedias de la ciudad. En segundo lugar, para demostrar el alcance real de las políticas de vivienda, se aplican las restricciones previstas en los programas a los hogares del AMCBA ordenados en deciles según su ingreso mensual, definiendo el porcentaje de hogares excluidos de las políticas de vivienda. Se analiza todo el período en que se han implementado los programas de financiamiento (2009-2015), utilizando los datos de la Encuesta Permanente de Hogares del INDEC. Se complementa con una distinción de hogares según su nivel socioeconómico (de acuerdo con datos de consultoras privadas e informes publicados por la (EPAL), demostrando la exclusión de grupos cada vez mayores de clase media y media baja.

Finalmente, se abre el debate respecto de las implicancias de los resultados y su aporte a los estudios en torno a la producción de hábitat urbano latinoamericano.

Políticas públicas de producción de vivienda. Ocupación del territorio y la vivienda individual como políticas de Estado

Debido a la escala del déficit habitacional que debe abordarse (Arriagada Luco, 2003), las políticas públicas nacionales y provinciales privilegian instrumentos masificadores, que simplifiquen su gestión y control, manteniendo como modelo de territorialización el de la vivienda unifamiliar en una parcela individual (Liernur y Ballent, 2014). Esto genera grandes extensiones urbanas monofuncionales altamente dependientes del centro de servicios de la ciudad, que requiere usuarios (idealmente, familias biparentales jóvenes con uno o dos hijos) con recursos suficientes como para que el costo de movilidad no incida mayormente en la economía familiar.

Este modelo fue consolidado por varios factores sociales y políticos: desde tiempos coloniales, la población fue en su mayoría propietaria de las viviendas que habitaba. Los inquilinos eran un grupo minoritario y generalmente en tránsito, que alquilaban viviendas y espacios de comercio por períodos breves, generalmente en casas de familia ${ }^{1}$. Hasta pasada la primera mitad del siglo XIX, la construcción de viviendas colectivas o edificios de alta densidad de uso no se consideraba una cuestión práctica en el territorio argentino, extenso y despoblado.

Esto continuó hasta las últimas décadas del siglo XIX, con las primeras migraciones masivas a las grandes ciudades del país. La mayor parte de la población que llegaba a las ciudades tenía escasos recursos, por lo que se instaló en los lugares más económicos. Las construcciones disponibles fueron subdividiéndose en unidades cada vez más pequeñas: durante la segunda mitad del siglo XIX aparecieron los primeros "conventillos" en las ciudades. Su número creciente, y las condiciones cada vez más insalubres a las que sometían a sus inquilinos no fueron ignorados por mucho tiempo. Antes de finalizar el siglo XIX, el conventillo fue visto como un verdadero "infierno moral" y un "engendro intrínsecamente destinado a producir el descontento y la degeneración". Debían erradicarse "la promiscuidad y la vagancia, la ebriedad y la disolución familiar que acechan tras estos 'vestíbulos de la muerte' que son los conventillos" (Cirvini, citado en Cravino, 2009).

Más allá de las condiciones reales de hacinamiento y promiscuidad que existían en los conventillos, la crítica tenía también un fin político. El escaso capital económico de sus habitantes era compensado en alguna medida por el capital social que se construía fortaleciendo las redes comunitarias con base en lazos de vecindad $y$ procedencia, situación favorecida enormemente por la vivienda colectiva. Esto fue visto no solo como un obstáculo para la nacionalización de la multitud inmigrante requerida por el proyecto político nacional hegemónico, sino que además, los patios de los conventillos configuraban el espacio ideal para asambleas de anarquistas y socialistas, tal como se vio en

\footnotetext{
${ }^{1}$ Para el caso específico de Córdoba, ver Luque Colombres, 1980.
} 
la huelga de alquileres de 1907. Por lo tanto, debía evitarse el contacto social entre los inquilinos, o controlarlo a través de la organización espacial (Liernur y Ballent, 2014).

A esto se sumaron la persistencia ideológica de "poblar el extenso territorio" y, por supuesto, las muy buenas oportunidades de rentabilidad que ofrecía a los terratenientes de las parcelas rurales periurbanas el patrón de urbanización por extensión, con parcelas individuales en la periferia de los pueblos y ciudades como la panacea para el crecimiento urbano. La vivienda unifamiliar en una parcela individual era concebida, entonces, no como una alternativa, sino como un derecho básico de la población al "aire puro y agua pura, tranquilidad y belleza campestre". Debido a esto, todos los planes de ordenamiento territorial de la época se concentraron en evitar tipologías multifamiliares.

Los escasos ejemplos de vivienda social colectiva fracasaron principalmente debido a factores específicos de diseño espacial, funcional y de gestión:

... falta de integración al medio urbano; ausencia de control del conjunto, indeterminación formal, obsolescencia [tipológica], grandes exigencias de mantenimiento; inobservancia de las tradiciones culturales ... y merma de la asistencia económica y social del Estado hacia comunidades formadas por personas de escasos recursos ...)

Obras que, por su gran envergadura y complejidad formal y organizativa solo pueden ser administradas, mantenidas y gestionadas con un fuerte apoyo público quedaron libradas a las posibilidades de acción de sus habitantes. El resultado fue que estos conjuntos ... mostraron un proceso de deterioro superior al que se registraba en la vivienda pública [individual] producida (Liernur y Ballent, 2014, pp. 307-311).

La suma de estas circunstancias terminó por consagrar la vivienda social colectiva como un mal urbanístico, social y político que debía evitarse a toda costa. La producción de vivienda social en Argentina en general, y en Córdoba en particular, fue definida por el modelo de la vivienda unifamiliar en parcelas individuales con densidades cada vez más bajas, producido masivamente en extensiones periurbanas. Este es el modelo que se continúa hasta la actualidad.
En el período analizado, la gestión del Estado nacional se encuadra en el modelo neodesarrollista (Barreto, 2012): partiendo de la situación de crisis económicopolítica ocurrida en el país en 2001, a partir de 2003 se propuso una ruptura con el paradigma neoliberal de gestión, en un proceso que tuvo continuidad hasta 2015. Durante esos años se

... implementó una política habitacional (y de infraestructuras territoriales) ... cuyo eje central fue la reactivación de la industria de la construcción como generadora de fuentes de empleos y de demandas para el mercado de la construcción. Una buena parte de ella tuvo el carácter de subsidio para los sectores más excluidos, e incluyó tanto la construcción de viviendas nuevas como acciones de mejoramiento habitacional y de urbanización de áreas deficitarias críticas (Barreto, 2010).

El modelo de urbanización masiva en extensiones suburbanas, mediante la producción en serie de viviendas unifamiliares en parcelas individuales es la base de la planificación estratégica de hábitat a nivel nacional de este período; esto se refleja en el Plan Estratégico Territorial Avance II: Argentina urbana (Ministerio de Planificación Federal, Inversión Pública y Servicios, MPFIPS, 2011).

En ese plan, prevalece este modelo sobre las intervenciones en áreas consolidadas o por consolidar, ya que tendría varias ventajas: a los ya conocidos fundamentos higienistas y de control social, se suman las críticas a la rigidez del trazado fundacional de las ciudades argentinas para albergar los nuevos usos y actividades que demanda el mercado inmobiliario, disminuyendo la rentabilidad y complicando su gestión y producción. $Y$ aunque inicialmente hace un diagnóstico equilibrado de las ventajas y desventajas del proceso de expansión y periurbanización, las políticas concretas se limitan a repetir este modelo consagrado de producción masificada de nuevo suelo urbano de baja densidad de ocupación. Las intervenciones sugeridas en áreas consolidadas (centrales, pericentrales e intermedias) se limitan a operaciones de recuperación del espacio público y normativa que promueva usos mixtos. Como resultado,

El Estado ha recuperado capacidad de promoción y ejecución centralizada, volcando una enorme 
cantidad de recursos en la producción de vivienda a través del Plan Federal. Sin embargo, pese a este gran esfuerzo, el plan consiste en lo que hemos denominado un tratamiento autónomo del "problema de la vivienda", extendiendo periferias de baja densidad de células repetitivas poco sensibles a los distintos cambios (demográficos, familiares, tecnológicos, ocupacionales) que transformaron la vida doméstica y a los grupos convivientes en las últimas décadas. Pero, sobre todo, prestando poca atención a los problemas urbanos (provisión de infraestructura y servicios, completamiento y generación de tejido urbano, intervención en áreas centrales deterioradas, etc.) y a sus consecuencias territoriales (Liernur y Ballent, 2014, p. 343).

Como resultado, el parque habitacional argentino está conformado en su mayoría por viviendas individuales (78,91\%), seguidas en cantidad por departamentos individuales $(16,75 \%)$ y otro tipo de viviendas más o menos precarias (4,34\%) (INDEC, 2012). Esta situación se repite en Córdoba (Tabla 1), con ciertos matices que se desarrollan a continuación.

Tabla 1

Evolución de la cantidad de viviendas por tipo en Córdoba, según censos

\begin{tabular}{|c|c|c|c|c|c|c|c|c|}
\hline & \multicolumn{2}{|c|}{1980} & \multicolumn{2}{|c|}{1991} & \multicolumn{2}{|c|}{2001} & \multicolumn{2}{|c|}{2010} \\
\hline & unid. & $\%$ & unid. & $\%$ & unid. & $\%$ & unid. & $\%$ \\
\hline TOTAL VIVIENDAS HABITADAS & 235.983 & $100 \%$ & 296.209 & $100 \%$ & 355.458 & $100 \%$ & 414.391 & $100 \%$ \\
\hline Casa tipo $A^{*}$ & 166.654 & $70,62 \%$ & 198.452 & $67 \%$ & 245.703 & $69,12 \%$ & 288.635 & $69,65 \%$ \\
\hline Casa tipo $\mathrm{B}^{* *}$ & 19.653 & $8,33 \%$ & 25.497 & $8,61 \%$ & 24.768 & $6,97 \%$ & 22.671 & $5,47 \%$ \\
\hline Departamento & 34.501 & $14,62 \%$ & 56.976 & $19,24 \%$ & 74.780 & $21,04 \%$ & 96.038 & $23,18 \%$ \\
\hline Rancho & 12.985 & $5,50 \%$ & 5.860 & $1,98 \%$ & 1.456 & $0,41 \%$ & 1.857 & $0,45 \%$ \\
\hline Casilla & & $0,00 \%$ & & $0,00 \%$ & 4.069 & $1,14 \%$ & 1.374 & $0,33 \%$ \\
\hline Pieza de inquilinato & 1.978 & $0,84 \%$ & 1.855 & $0,63 \%$ & 2.961 & $0,83 \%$ & 1.959 & $0,47 \%$ \\
\hline Pieza en hotel o pensión & & $0,00 \%$ & & $0,00 \%$ & 872 & $0,25 \%$ & 1.231 & $0,30 \%$ \\
\hline Local no construido para habitación & 212 & $0,09 \%$ & 953 & $0,32 \%$ & 818 & $0,23 \%$ & 439 & $0,11 \%$ \\
\hline Vivienda móvil & & $0,00 \%$ & & $0,00 \%$ & 31 & $0,01 \%$ & 33 & $0,01 \%$ \\
\hline
\end{tabular}

* Casa tipo A: todas las viviendas no consideradas tipo B.

** Casa tipo B: son aquellas que cumplen con, al menos, una de las siguientes condiciones: tienen piso de tierra, no tienen provisión de agua por cañería dentro de la vivienda, o no disponen de baño con descarga de agua.

Fuente: Datos censales procesados por la Dirección de Estadística y Censos de Córdoba, DEyC, en su portal web http://estadistica.cba.gov.ar

\section{Parque habitacional en Córdoba}

El parque habitacional existente en la ciudad está determinado, en primer lugar, por factores macroeconómicos que hacen que la actividad inmobiliaria y de la construcción esté entre las más importantes de la ciudad (Boccolini, 2017a), produciendo el 16,4\% del Producto Bruto General de la ciudad (Elorza, 2016). En los últimos años, la producción de hábitat aumenta cada vez más: aunque los hogares se incrementaron un $9 \%$ entre 1991 y 2001 , y un $4 \%$ entre
2001 y 2010, la cantidad de viviendas aumentó un 35\% y un $14 \%$ respectivamente (DEyC). Como consecuencia, por un lado, el parque habitacional existente es de construcción relativamente reciente $(22,3 \%$ tiene menos de 10 años y el 55,6\% entre 10 y 49 años); por otro lado, y a diferencia de la tendencia nacional, en los últimos años hay un crecimiento del parque habitacional mayor de lo esperable de acuerdo solamente con el crecimiento poblacional (Figura 1). 


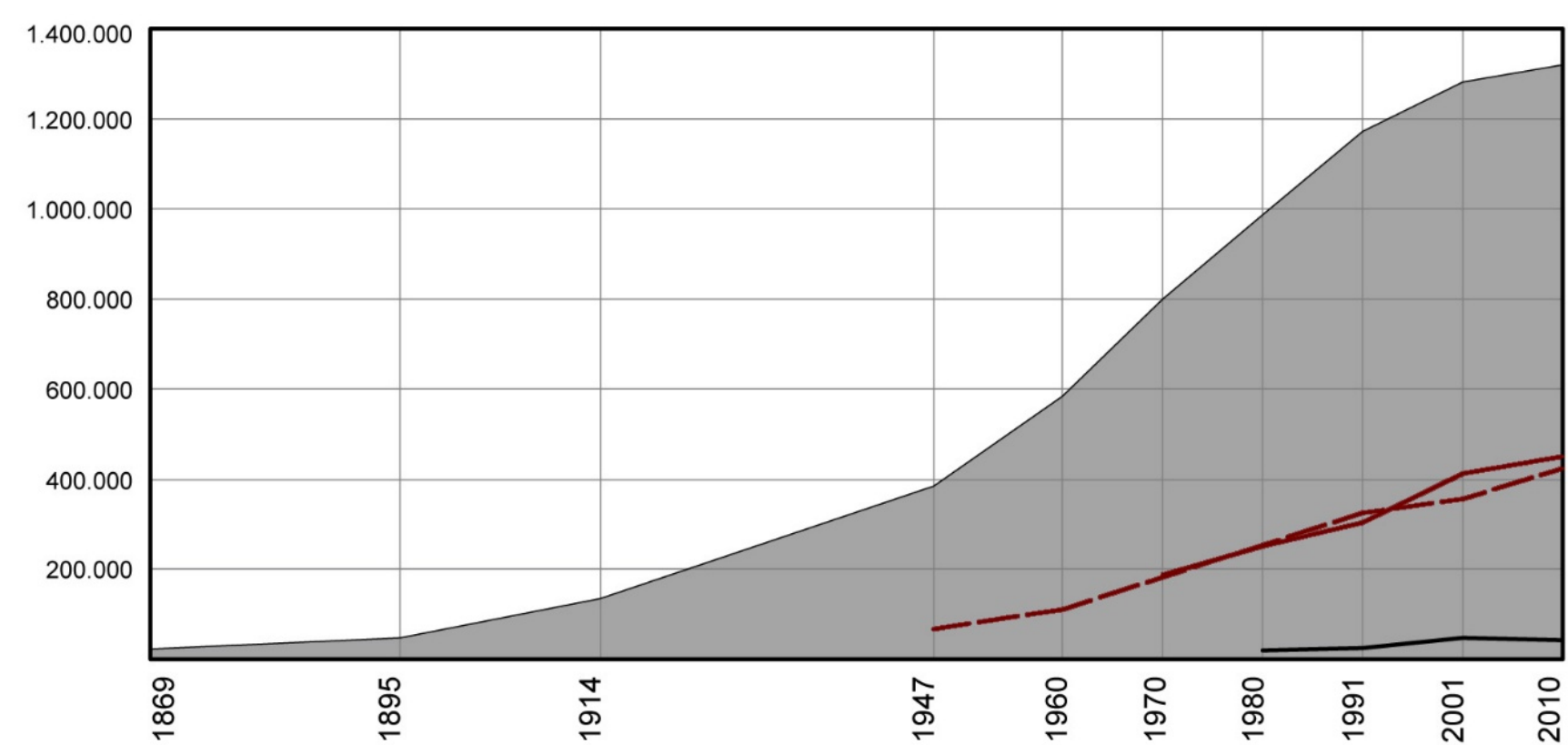

Población total

Cantidad de viviendas

- Cantidad de hogares

C Cantidad de viviendas vacías

Figura 1. Crecimiento de la población, comparado con la cantidad de hogares y viviendas en Córdoba. Fuente: Elaboración propia con base en datos de DEyC.

Sumado a esto, Córdoba tiene una de las menores proporciones de viviendas deficitarias del país, incluso menor a otros grandes centros urbanos como Buenos Aires, Rosario y Mendoza (INDEC, 2012): los departamentos y las casas tipo " $\mathrm{A}$ " son las tipologías de mayor crecimiento en los últimos años, superando el $92 \%$ del total (Tabla 1 ).
Aun así, el $16,76 \%$ de las viviendas tiene algún tipo de déficit material recuperable o hacinamiento, y el 1,58\% es directamente irrecuperable (Tabla 2). Sin embargo, debido en gran parte a las políticas de regularización (mediante saneamiento de títulos o erradicación a urbanizaciones formales) de los últimos años, hay una tendencia decreciente en la proporción de viviendas con tenencia irregular, mientras que los hogares dueños de la vivienda y el terreno e inquilinos formales son cada vez más numerosos (Figura 2).

Tabla 2

Evolución de la cantidad de viviendas por tipo de déficit en Córdoba, según censos

\begin{tabular}{|c|c|c|c|c|}
\hline \multirow{2}{*}{ Situación habitacional } & \multicolumn{2}{|c|}{2001} & \multicolumn{2}{|c|}{2010} \\
\hline & Hogares & $\%$ & Hogares & $\%$ \\
\hline Hogares que ocupan viviendas irrecuperables & 6.534 & $1,82 \%$ & 6.534 & $1,58 \%$ \\
\hline Hogares que ocupan viviendas recuperables & 30.088 & $8,37 \%$ & 30.088 & $7,26 \%$ \\
\hline Hogares que padecen hacinamiento & 57.952 & $16,12 \%$ & 39.349 & $9,50 \%$ \\
\hline TOTAL de hogares con déficit & 75.971 & $21,14 \%$ & 75.971 & $18,34 \%$ \\
\hline TOTAL hogares en la ciudad & 359.404 & $100 \%$ & 414.237 & $100 \%$ \\
\hline
\end{tabular}




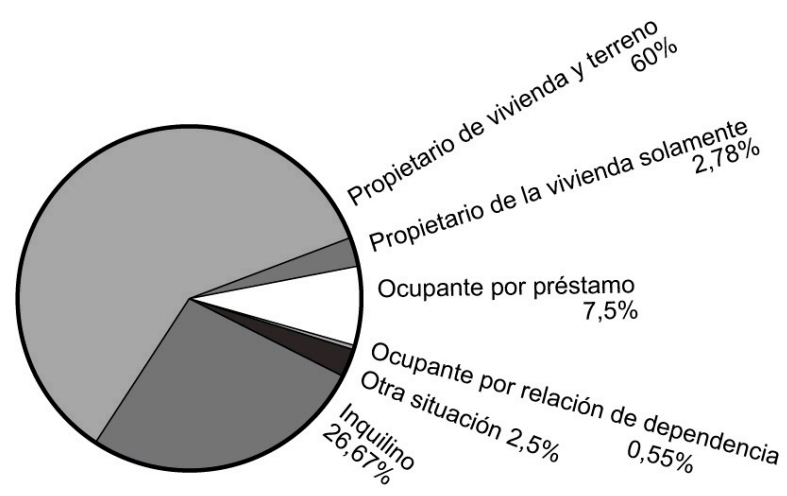

Figura 2. Hogares según régimen de tenencia de la vivienda en Córdoba.

Fuente: Elaboración propia con base en datos de DEyC.
A pesar de esto, la mayoría de los barrios pericentrales y en el área intermedia de Córdoba (entre las de mayor calidad ambiental y urbana de la ciudad) disminuyen su población constantemente desde el año 2001 (Figura 3). Estos barrios abarcan el $46 \%$ de la superficie urbanizada, e incluyen el $47 \%$ de las viviendas existentes en la ciudad.

Simultáneamente, a pesar de ser el centro urbano que concentra la mayor cantidad de población y actividades productivas de la provincia, su tasa de crecimiento se ha reducido y pierde importancia frente a las de ciudades medianas y pequeñas del Área Metropolitana de Córdoba (AMCBA), como muestra la Figura 4.

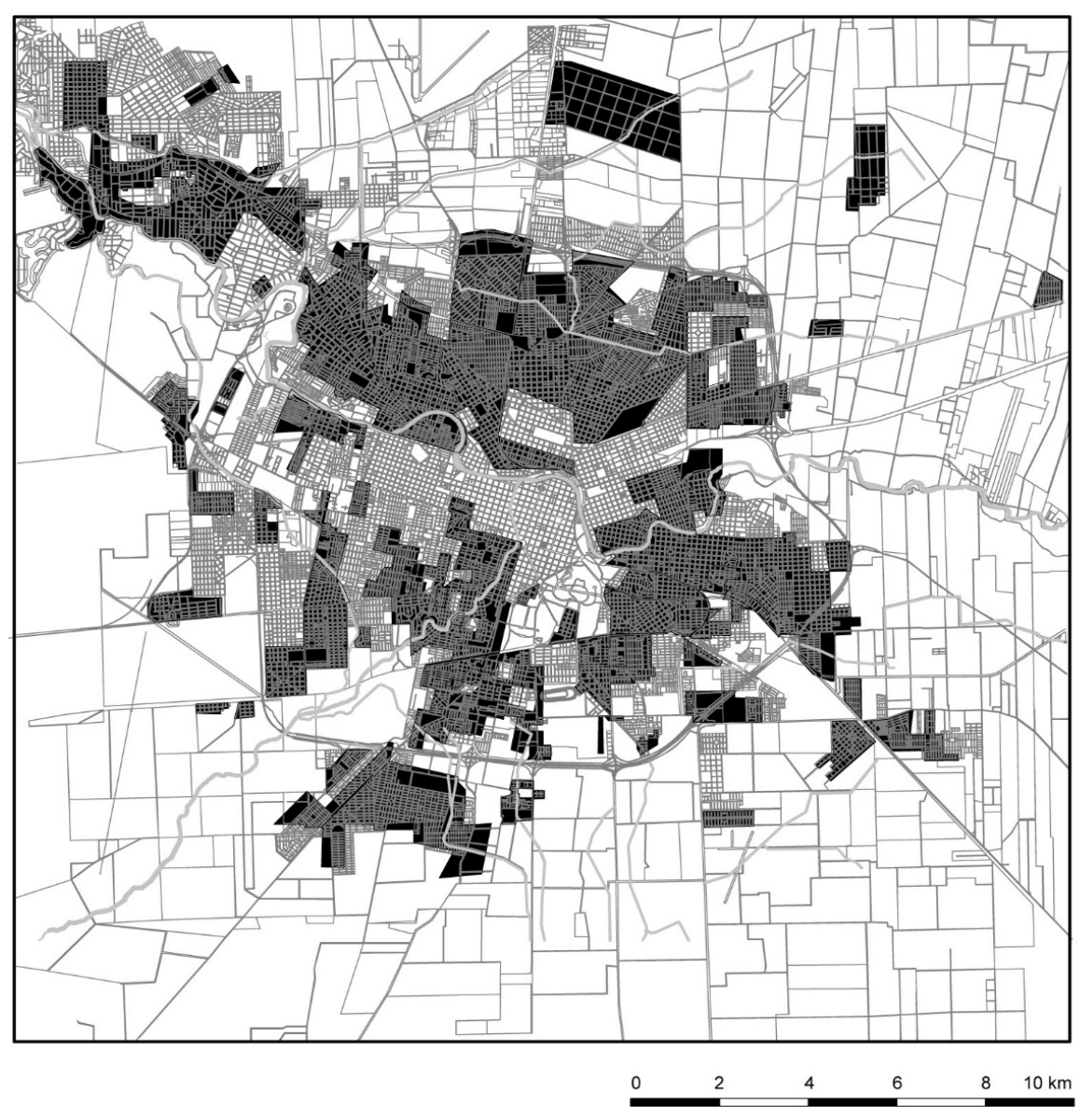

Barrios que han disminuido su población en el periodo intercensal 2001-2010

Figura 3. Barrios de la ciudad con disminución poblacional en el período 2001-2010.

Fuente: Peralta y Liborio (2014). 


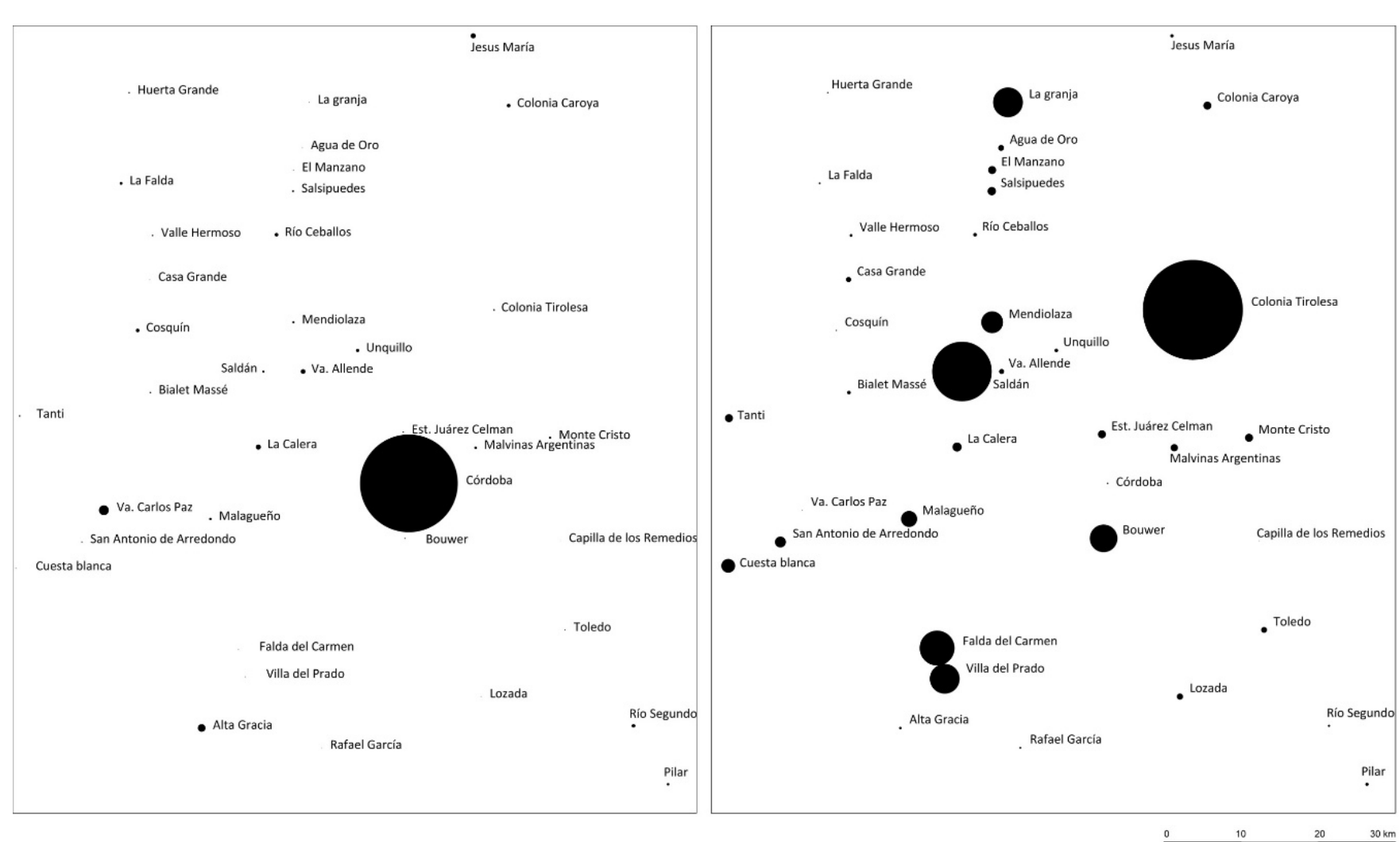

Figura 4. AMCBA. Principales centros urbanos según cantidad de población (izquierda) y según tasas de crecimiento demográfico (derecha). Fuente: Elaboración propia con base en datos de Google Maps y DEyC.

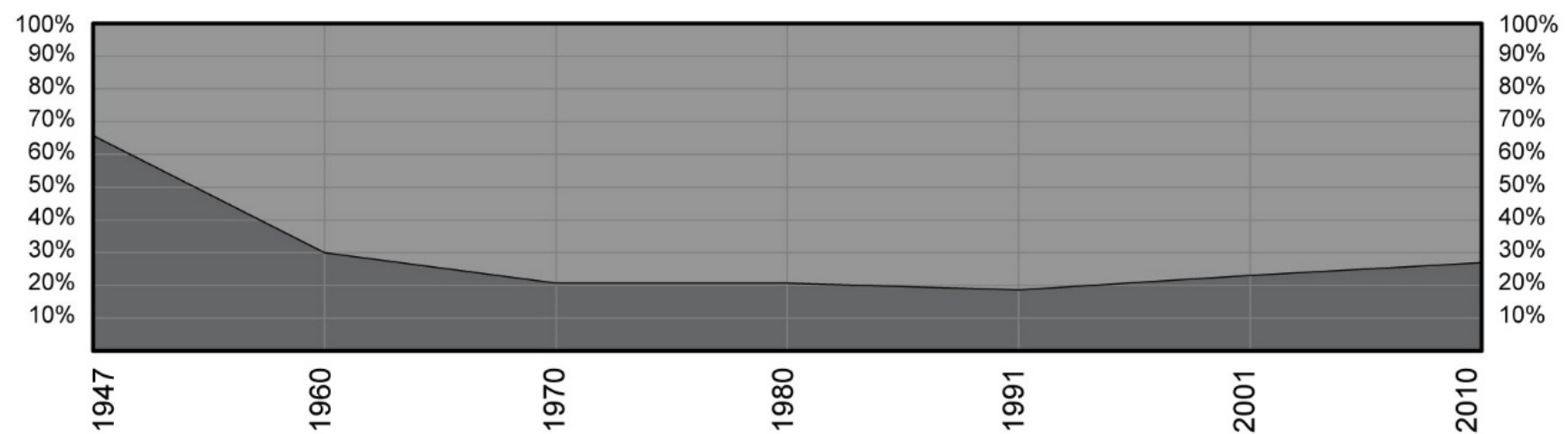

Hogares propietarios

Hogares inquilinos

Figura 5. Evolución de la relación entre hogares inquilinos y propietarios en Córdoba.

Fuente: Elaboración propia con base en datos de DEyC.

Por otro lado, la tendencia de primacía de hogares propietarios de su vivienda se ha revertido desde fines del siglo $\mathrm{XX}$, con un aumento de los hogares inquilinos mayor al 30\% entre 1991 y 2010 (Figura 5).

Esto contradice el resultado esperable de las políticas públicas de producción de vivienda, que concentran su producción en los grandes centros urbanos, y restringen su tenencia al régimen de propiedad individual. Sin embargo, el análisis muestra que estas políticas fomentan dichas tendencias, como se desarrolla a continuación. 


\section{Concentración de la producción y los beneficios}

La producción de vivienda social es rentable. Esto lo demuestran las grandes empresas privadas dedicadas en Argentina a la obra pública y su crecimiento económico cualquiera sea el período histórico analizado (Yujnovsky, 1984). La contradicción es que, aunque sea rentable, la gran mayoría de sus consumidores no están en condiciones de afrontar -individualmente- el precio de mercado de estos bienes.

Esta contradicción, que genera el déficit habitacional urbano, es resuelta en Argentina asignando recursos del Estado a sufragar la producción de hábitat. Esto implica presupuestos significativos invertidos en distintos rubros del sector de producción y gestión privado a través de diversos instrumentos operativos, organizados según la doble estrategia de "facilitación/focalización" del mercado de la vivienda. Facilitación, proponiendo productos habitacionales con créditos hipotecarios blandos, y focalización con la inversión del Estado centrada en la producción de urbanizaciones de vivienda o la urbanización de asentamientos existentes. Pero el hecho de que el Estado participe en el mercado productivo de hábitat como un actor particular más (MPFIPS, 2011), implica tomar parte en los procesos de concentración de poder y recursos característico de la urbanización de capitales neoliberal.

El caso paradigmático es la producción directa de hábitat, en un mercado de tierras que no posee un régimen jurídico de la propiedad de la tierra orientada al hábitat como bien social. Al desarrollar programas de producción o financiamiento habitacionales, el Estado se ve obligado a adquirir tierra en un escenario de escasez que él mismo ha producido, consiguientemente a valores superiores a los previos a la implementación de esos programas. Además, desarrolla obras de infraestructura y servicios complementarios, que generan valorización del suelo urbano, y cuya plusvalía es capturada íntegramente por los propietarios de la tierra. Finalmente, necesita materiales, mano de obra y gestión de obras y proyectos que son obtenidos compitiendo como un actor más en el mercado de la construcción.

Sumado a eso, el Estado subsidia el mercado de la vivienda para ampliar los grupos de consumo de la producción privada: financiando a los consumidores para que puedan acceder a los precios de mercado, permitiendo a los agentes inmobiliarios mantener valores que garantizan rentabilidad a los grandes desarrollistas. No se transforman o eliminan los mecanismos de captura de beneficios estructurados por el mercado inmobiliario privado: los fondos del Estado no se asignan a redistribuir la riqueza entre la comunidad, sino a subsidiar a los productores capitalistas.

Esto explica la aparente contradicción entre la política supuestamente redistributiva del gasto público destinado a subsidiar la vivienda y la política de concentración y estabilización económica en las grandes empresas constructoras, que se ha mantenido casi constante a lo largo de gobiernos conservadores, liberales, populistas y neoliberales, tanto privatistas como estatizadores, y a pesar de las numerosas crisis políticas, económicas e institucionales que ha atravesado el país desde fines del siglo XIX.

Esto también permite entender porqué en Argentina nunca llegaron a tener significación operaciones de vivienda popular difundidas en otros países -e incluso propiciadas por organismos internacionales como el Banco Interamericano de Desarrollo (BID) o el Banco Mundial- como las parcelas con servicios, el mejoramiento de vivienda, la urbanización de asentamientos irregulares o el apoyo a la autoconstrucción. Cualquiera de ellos hubiera significado repartir el botín con sectores excluidos de la alianza [entre el Estado y los grandes contratistas], ya fueran pequeñas o medianas empresas, organizaciones no gubernamentales, grupos de base [o los mismos beneficiarios individuales] (Cuenya, 1992, 40).

A pesar de esto, es innegable que las políticas públicas han aumentado la oferta de hábitat urbano; el punto es determinar cómo se materializan en el territorio, y qué impacto tienen en la estructura urbana: estos mecanismos de concentración de la producción se concretan en instrumentos políticos a través de los cuales se territorializarán las políticas habitacionales.

\section{Producción directa de viviendas}

En Córdoba, la producción directa de hábitat por parte del Estado ha sido destinada en casi su totalidad a los sectores de menos recursos de la población, en situación de riesgo ambiental o material. 
Las gestiones del Estado municipal se limitan al mejoramiento de 106 viviendas en el período 1999-2003 y -dentro del Plan Federal de Emergencia Habitacionala la gestión de 160 viviendas ejecutadas por cooperativas entre 2003 y 2007. En comparación, es el Estado provincial el que lleva adelante los programas más significativos cuantitativamente en producción directa de hábitat: durante el período 2000-2007 se entregaron 2.042 viviendas producidas por la gestión del Instituto Provincial de Vivienda, destinados a clases medias y medias bajas. A partir de ese momento, y hasta 2015, el programa Hogar Clase Media entregó 200 viviendas individuales en la ciudad. Por su parte, el programa De inquilino a propietario (ejecutado por el Ministerio de Obras y Servicios Públicos, el Banco de Córdoba, la Cámara Argentina de la Construcción -delegación Córdoba- y la Cámara Empresarial de Desarrollistas Urbanos Córdoba) entregó más de 500 unidades, tanto de viviendas individuales como de departamentos (Elorza, 2016).

Sin embargo, es el programa Mi casa, mi vida el que mayor impacto cualitativo y cuantitativo ha tenido en la producción de hábitat: este programa fue financiado mayormente por el BID, el Fondo Nacional de Vivienda (FoNaVi) y el Plan Federal de Viviendas. Estuvo destinado a la erradicación de población desde lugares de riesgo ambiental a urbanizaciones en la periferia y entregó 8.876 nuevas viviendas:

... desde 2003 hasta 2010, se ha desarrollado un programa de relocalización de asentamientos informales a nuevos barrios, en el marco del cual se han trasladado aproximadamente 70 asentamientos a 41 nuevos barrios, de los cuales 11 son denominados como 'barrios-ciudad', diferenciados por su escala, que supera las 500 viviendas. La localización de los conjuntos habitacionales configura una nueva distribución de la población pobre en la ciudad: ha sido trasladada desde el anillo central e intermedio a los anillos periféricos; por lo general se la localiza en áreas de extensión urbana, la mayor parte de las veces incorporando suelos que estaban afectados al uso rural. Resultados de diversas investigaciones estarían demostrando que esta política ha contribuido a la ruptura de redes laborales y de ayuda mutua de las familias relocalizadas y a la reproducción de pobreza en estos nuevos barrios. (Elorza, 2009).

Estos resultados contrastan fuertemente con proyectos nacionales de radicación de la población y mejoramiento del hábitat; uno de ellos es el Programa de Mejoramiento de Barrios (ProMeBa): desde 2000 y hasta 2015, se ejecutaron en la ciudad obras por AR\$44.483.700, que se estima benefician a más de 10.000 hogares. El ProMeBa se complementa con programas de regularización dominial de asentamientos informales localizados en tierras fiscales, como Arraigo, Raíces y Nuestra Tierra (Elorza, 2016). Estos programas de radicación tienen como objetivos controlar social y políticamente a los grupos más vulnerables en el territorio y ampliar el mercado inmobiliario y la base fiscal de tributación del gobierno local.

\section{Financiamiento a la demanda y liberalización de la producción}

El mercado de alquileres no ha sido objeto de políticas públicas explícitas que regulen el alquiler de vivienda como bien de carácter social. Los instrumentos de mayor impacto en el acceso al hábitat urbano para hogares de ingresos medios y medios altos han sido las políticas públicas de financiamiento hipotecario subsidiado con fondos estatales.

En el período analizado, el Estado provincial fue el primero en implementar el financiamiento de acceso al hábitat para clases medias, rol que había quedado vacante después de los programas del Banco Hipotecario Nacional de mediados del siglo XX. En 2007, el Banco de Córdoba (provincial) lanzó una línea de créditos hipotecarios a tasa fija destinado a familias de clase media para la vivienda propia. Entre 2010 y 2011 desarrolló las líneas Tu Casa y Tu Hogar, destinadas a la compra de vivienda nueva o casi nueva (de no más de cuatro años de antigüedad), o bien, para construcción. El gobierno provincial programaba otorgar más de diez mil créditos a un plazo de entre 15 y 20 años (Capdevielle, 2014).

El financiamiento para clases medias mantuvo su continuidad con el desarrollo a partir del año 2012 del ProCreAr, financiado por la Administración Nacional de la Seguridad Social (ANSES), el Ministerio de Economía y el Banco Hipotecario. Este programa, destinado a la 
construcción o compra de viviendas o departamentos, ha financiado la construcción de 22.003 viviendas en la provincia de Córdoba.

\section{Territorialización de las políticas públicas de acceso al hábitat}

La localización de los proyectos de vivienda social para hogares de bajos recursos ineludiblemente en la periferia urbana, en áreas con deficientes servicios y equipamiento urbano, y escasa conexión con el resto de la ciudad ha sido evaluado y demostrado en diferentes trabajos (Elorza, 2016; Tecco y Fernández, 2005; entre otros). Por razones financieras o políticas, la expulsión de Córdoba que sufren los hogares relocalizados es una premisa inherente a estos programas. Sin embargo, los programas de financiamiento no tienen restricciones explícitas de localización. Su impacto en procesos de expulsión de clases medias se debe indirectamente a restricciones financieras

En efecto, el modelo de parcela individual con una vivienda unifamiliar de los proyectos de vivienda social caracteriza también a las viviendas construidas con financiamiento hipotecario estatal: los programas provinciales y nacionales, aunque contemplan la compra de casas o departamentos, están destinados principalmente a la construcción de viviendas en terreno propio (Gargantini, 2014). Y aunque el ProCreAr incluye proyectos de conjuntos de viviendas, más del $70 \%$ de los créditos hipotecarios son destinadas a emprendimientos individuales.

A esto se suma el valor máximo de la parcela impuesto por los programas de financiamiento -en el caso del ProCreAr, fue de AR\$180.000 (aproximadamente US\$13.403) en 2015-. En el mercado inmobiliario de Córdoba esta condición, junto con la inexistencia de políticas de regulación del mercado de suelo y la inevitable especulación que se desprende de ello, es uno de los detonantes principales para incentivar la compra de terrenos en el AMCBA, donde el valor del suelo urbano está por debajo de ese valor (Figura 6). Esto es una de las principales causas del desplazamiento de población desde Córdoba hacia centros menores del AMCBA, es decir, la contraurbanización.

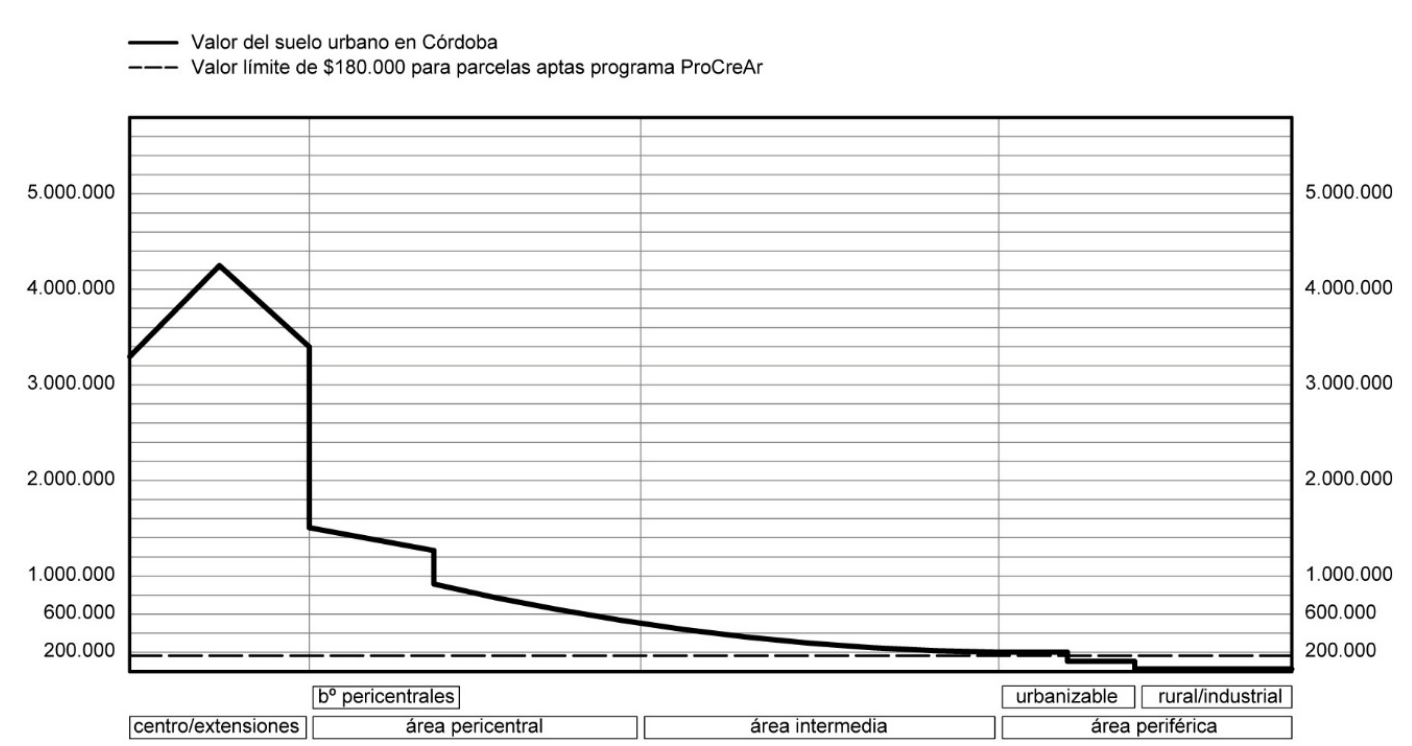

Figura 6. Variación del valor del suelo urbano en el cuadrante Sureste de la ciudad. Se ha tomado como referencia una parcela de 360 m², y valores del suelo (sin mejoras) correspondientes al último trimestre del año 2015.

Fuente: Elaboración propia sobre la base del relevamiento del mercado inmobiliario, la investigación Valores del suelo en América Latina, del Lincoln Institute y DGEyC.

Por su parte, el requisito de antigüedad máxima de 4 años para la compra de inmuebles significa la imposibilidad de adquirir viviendas en gran parte de los barrios consolidados en áreas pericentrales e intermedias, y promueve la compra de propiedades en las nuevas urbanizaciones periurbanas. Esto intensifica el proceso de crecimiento por extensión de muy baja densidad, agravando cada vez más la distensión de la 
estructura urbana con un modelo de territorialización que ha sido descripto como un "monocultivo de viviendas". También disminuye la posibilidad de que los nuevos hogares accedan a las viviendas vacantes en esas áreas, acelerando el éxodo a la periferia y al AMCBA.

\section{Hogares beneficiados por las políticas públicas de acceso al hábitat}

Si bien el objetivo de las políticas de incentivar la actividad económica está comprobado, aunque se trate de efectos a corto y mediano plazo (IERIC, 2016), el objetivo de ampliar el acceso al hábitat ofrecido por el mercado inmobiliario privado es más discutible:

- Por un lado, el criterio para asignar las soluciones habitacionales o de mejora del hábitat para los grupos con menos recursos no dependen de las necesidades concretas de una comunidad o grupo familiar, sino de localizaciones en el territorio (caso de Mi casa, mi vida) o de estrategias políticas de diversa índole.

- Por otro lado, el financiamiento al acceso al hábitat destinado a la clase media ha sido otorgado principalmente a los sectores con más recursos económicos. El $70 \%$ de los créditos otorgados por el ProCreAr fueron destinados a hogares que están dentro del $40 \%$ de los más ricos del país, en las grandes áreas metropolitanas (Ciocca, 2015). Esto explica -principalmente, aunque hay otros motivosla "elitización" de los productos inmobiliarios destinados a esta financiación. Aparecen productos específicos para los nuevos grupos de demanda que acceden al financiamiento, pero siempre dentro de los valores de mercado ya establecidos por los grupos de mayores recursos (produciendo una distorsión importante tanto cualitativa como cuantitativa, es decir, de oferta y precios).

El alcance de las políticas públicas de acceso al hábitat se demuestra en la Tabla 3. 
Tabla 3

Distribución de los hogares del AMCBA en deciles según ingreso familiar, por trimestre. Período 2005-2015

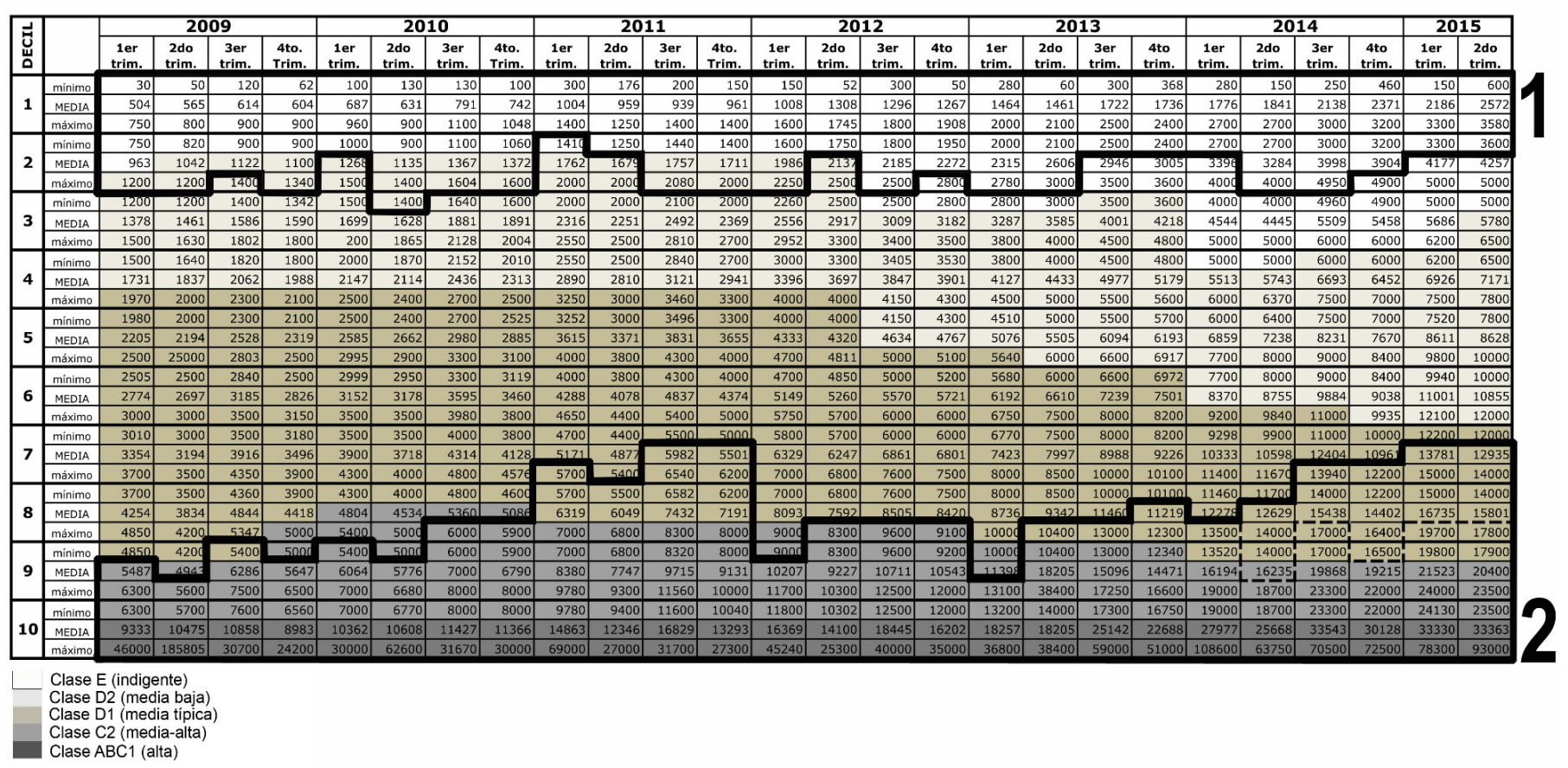

Fuente: Elaboración propia sobre la base e datos de la Encuesta Permanente de Hogares realizada por el INDEC.

Notas:

a) El gradiente de grises indica la pertenencia a cada grupo socioeconómico.

Fuente: Para el año 2010, Asociación Argentina de Marketing; para el año 2001 (no presente en esta tabla, pero usado de referencia), Mora y Araujo (2002); otros períodos anuales: extrapolación de datos con base en información para el total del país y datos de años 2010 y 2001.

b) Las líneas gruesas indican la posibilidad de acceder a la vivienda propia de acuerdo al ingreso familiar.

- Polígono 1: Agrupa los hogares cuyo ingreso mensual es inferior a un salario mínimo vital y móvil, por lo cual indefectiblemente requieren asistencia estatal para acceder a su vivienda.

Fuente: Ministerio de Trabajo, Empleo y Seguridad Social.

- Polígono 2: Agrupa los hogares cuyo ingreso mensual les permite acceder a un crédito financiado por el Estado para la construcción de una vivienda de dos dormitorios, o no tienen necesidad de financiamiento. El monto de construcción se ha calculado para una vivienda de $75 \mathrm{~m}^{2}$, según el costo oficial de la construcción en Córdoba para diciembre de cada año.

Fuente: Para el período 2012-2015, datos suministrados por el portal web del ProCreAr, línea Construcción con terreno. Para el período 2009-2011, datos suministrados por el Banco de la Provincia de Córdoba (BANCOR), programa Tu Casa-Construcción, y DGEyC.

El criterio para delimitar el grupo (1) de ese cuadro tiene que ver con la falta de condiciones estables para seleccionar hogares candidatos a la vivienda producida directamente por el Estado: sus operaciones no contemplan postulaciones individuales a los programas de asistencia, por lo que no hay un criterio de selección individual de beneficiarios. A esto se suma la discrecionalidad en criterios de actuación. Por lo tanto, y a los fines de esta investigación, se determina que un ingreso familiar menor al salario mínimo, vital y móvil impide destinar los recursos familiares a la obtención de una vivienda digna en el mercado formal, siendo indispensable la asistencia estatal; se considera entonces a este grupo como destinatario de las políticas públicas de producción directa.

El criterio para definir el grupo (2) es determinar los hogares con ingresos suficientes para acceder al financiamiento estatal, suponiendo que se dispone de una parcela donde construir la vivienda. La tipología de dos dormitorios se define como referencia debido a la evolución posible del grupo familiar destino de este financiamiento y el plazo de cancelación de la hipoteca (20 a 30 años).

Hasta 2013 se supone que la cuota para cancelar la hipoteca será equivalente al $30 \%$ del ingreso familiar y a partir del año 2014, equivalente al $40 \%$ (de acuerdo con 
los requisitos de cada plan de financiamiento). Se señala con una línea de trazos los hogares que verían afectado su ingreso entre $31 \%$ y $40 \%$ con la cuota de cancelación del crédito.

A pesar de que los hogares que quedan fuera de estos dos grupos son casi la mitad del total de hogares de la ciudad, para el trazado de ambas líneas de acceso a la vivienda propia se han elegido números conservadores.

Por un lado, añadir variables como la discrecionalidad en la asignación de soluciones habitacionales para sectores críticos, o contrastar cuantitativamente las soluciones habitacionales construidas con el déficit existente reduciría el grupo (1). Por otro lado, tener en cuenta el costo $/ \mathrm{m}^{2}$ de construcción real según proveedores y constructores (por ejemplo, en 2015 el costo oficial era de $A R \$ 7.701,30 / \mathrm{m}^{2}$ y el costo real era de $A R \$ 8.500$, diferencia del 11\%; en 2014, el costo oficial era de $A R \$ 6.641 / \mathrm{m}^{2}$ y el costo real era de $A R \$ 7.500$, diferencia del $13 \%$, según datos obtenidos en entrevistas con diversos profesionales del medio que trabajan específicamente con las líneas de crédito de BANCOR y ProCreAr), o incluir el costo de la parcela reduciría exponencialmente el grupo (2).

En Córdoba, la gran cantidad de población flotante (debida entre otras causas a los estudiantes y posgraduados de las universidades que se instalan más o menos temporalmente en la ciudad) (Boccolini, 2017c) ha sido considerado el principal estructurador del mercado de inquilinos en la ciudad. Sin embargo, y reconociendo la importancia de esta población flotante para el sistema urbano cordobés, queda demostrado en el análisis que el desarrollo del mercado de inquilinos depende en, gran medida, de las estrategias de urbanización de capitales y los nuevos hogares generados en los grupos excluidos del mercado de producción de viviendas para la compra, tal como se explica en la Tabla 3.

Pese a las fuertes políticas del Estado, de los aproximadamente 5.500 nuevos hogares que se generan por año en el AMCBA en el período analizado, entre un $60 \%$ y un $45 \%$ de ellos no son capaces de acceder a la vivienda propia, ya sea con sus propios recursos, financiados, o a través de vivienda social construida por el Estado. Y si bien hay un pequeño porcentaje de nuevos hogares que reciben su vivienda como préstamo (o adelanto de herencia), o que ingresan al mercado informal, la gran mayoría de estos nuevos hogares accede al mercado de vivienda como inquilinos.

Como consecuencia, la inquilinización es cada vez más relevante dentro de las estrategias de acceso al hábitat urbano en Córdoba. Significa, cada año, 2.400 a 3.300 nuevos hogares en la ciudad (DGEyC) que se instalan en una vivienda compartida, en préstamo, obtenida a través del préstamo o donación, o, en su inmensa mayoría, se convierten en hogares inquilinos, lo que explica los altos índices de inquilinización urbanos en un escenario tradicionalmente dominado por los propietarios de viviendas individuales.

\section{Discusión y conclusiones}

Los resultados verifican la hipótesis propuesta: las políticas públicas de producción de vivienda influyen enormemente en las estrategias de acceso al hábitat urbano, aun cuando se reconoce su articulación compleja con otros factores.

Las mismas fomentan la contraurbanización, debido a que las políticas públicas de vivienda no solo aumentan los valores originales, sino que obligan a la adquisición de parcelas desocupadas en la periferia o en ciudades y pueblos del AMCBA. Esto sobrecarga la estructura urbana de la ciudad (obligando a permitir la extensión de la urbanización sobre suelo antes rural o de reserva natural), y colapsa la de los pequeños centros que no están preparados para estas tasas de crecimiento; además fomenta el vaciamiento de las áreas intermedias y pericentrales de la ciudad, a pesar de que estas cuentan con una de las más completas infraestructuras de equipamiento y servicios de todo el AMCBA.

No solo se encarece el funcionamiento y mantenimiento de la infraestructura de servicios al extenderse cada vez más en el territorio (mientras que la infraestructura existente se subutiliza): el patrón de territorialización predominante adolece precisamente de la condición de "urbanidad" y acceso al hábitat urbano que se pretende para sus beneficiarios. Pero mientras que la paradoja de la expulsión de la ciudad por medio de la producción de vivienda social de los grupos más desfavorecidos ha sido desarrollada ampliamente, todavía no hay estudios suficientes del impacto que esto tiene en las urbanizaciones de clase media y media-alta del ProCreAr. 
Por otro lado, la inquilinización en el contexto local es un proceso de pauperización de las condiciones de acceso al hábitat, y aumenta la exclusión de grupos socioeconómicos cada vez más numerosos: en los últimos años (2010-2015) los contratos de alquiler determinan generalmente un incremento del $20 \%$ semestral, mientras que los salarios no afectados por negociaciones sindicales tienen ajustes de menos del $9 \%$ (INDEC, 2012; DGEyC y relevamiento realizado en inmobiliarias locales). Los inquilinos deben adecuar sus necesidades a la oferta de los propietarios rentistas en cuanto a funcionalidad, espacio, ubicación, servicios y renta a pagar para hacer uso de las propiedades. Los propietarios, por su parte, pueden determinar la renta de su propiedad sin considerar situaciones de competencia con otros propietarios, incluso retirarla del mercado si no se cumplen condiciones mínimas de rentabilidad.

El proceso de inquilinización bajo condiciones no reguladas de oligopolio conduce a la inestabilidad habitacional permanente de estos hogares. Ajustes en los precios del alquiler e inequidades en las negociaciones con propietarios o administradores, hacen que muchos de estos hogares deban cambiar de vivienda alquilada casi a cada término de contrato ( 2 años). El constante "peregrinaje urbano" implica no solo la reducción paulatina en la superficie de la vivienda (Boccolini, 2017a), sino que es, además, centrífugo: los valores de los alquileres aumentan constantemente, expulsando lentamente la población desde áreas centrales (donde los beneficios de escala y urbanización compensan la falta de espacio, por ejemplo) hacia áreas intermedias, periféricas, o directamente a localidades vecinas del AMCBA.

Finalmente, los resultados de esta investigación coinciden con los de las investigaciones existentes acerca de las políticas de vivienda en Argentina: no solo no se ha revisado críticamente el modelo de ocupación territorial forjado hace más de 150 años por la connivencia hegemónica político-económica; las políticas habitacionales se concretan en instrumentos de concentración de la riqueza en lugar del rol redistributivo que se pretende asignarles: tanto a nivel nacional como provincial y municipal han estado estructuradas no tanto por el objetivo de producir hábitat eficiente para la demanda de la población, sino por el hecho de que la industria de la construcción de hábitat -y sobre todo, la construcción de hábitat urbano- se ha mostrado como un instrumento regulador de la economía a nivel nacional.

Es evidente que las políticas del Estado utilizan el modelo de urbanización que produce más rentabilidad a los propietarios de la tierra y constructores (extensiones periurbanas homogéneas de parcelas individuales; construcción de viviendas unifamiliares en muy baja densidad; obras de infraestructura vial que reducen las deseconomías de costos y tiempo de transporte; producción seriada a gran escala), y una escala de producción que beneficia específicamente a los grandes agentes del mercado privado: el sistema productivo de hábitat en serie solo puede ser afrontado por los grandes desarrollistas, que lo ajustan para maximizar su rentabilidad, en desmedro de la flexibilidad funcional, espacial o la riqueza en el tejido urbano producido. Las premisas de "ocupar el territorio" y "gobernar es poblar" deben ser discutidas en un marco realista de producción de hábitat de calidad y sostenible social, productiva y ambientalmente.

El impacto de las políticas públicas de producción de vivienda que se verifica en esta investigación pone en disputa una condición estructural de la producción de vivienda social, cualquiera sea el modelo de gestión, el patrón de territorialización, la escala de intervención y el presupuesto destinado a ella: no puede entenderse la producción social de vivienda sin una estructura política, jurídica y económica que contemple la producción de hábitat (en este caso, el hábitat urbano) como un bien social, accesible a toda la comunidad. Solo así podrán encararse políticas habitacionales que reduzcan el déficit de vivienda crónico que afecta a los ciudadanos, y promuevan el acceso al hábitat de calidad a toda la comunidad [B] 


\section{Referencias}

Arriagada Luco, C. (2003). América Latina: información y herramientas sociodemográficas para analizar $y$ atender el déficit habitacional. Santiago de Chile: Naciones Unidas. Recuperado de https://goo.gl/TRrhpn

Arqueros Mejica, M. S., Gil y de Anso, M. L., Mendoza, M., y Zapata, M. C. (2008). Córdoba y Mendoza: dos casos para pensar la producción social del hábitat. Revista INVI, 23(62), 21-73. Recuperado de https://goo.gl/Nzq9tf.

Barreto, M. Á. (2010). El concepto de "hábitat digno" como meta de una política integral de áreas urbanas deficitarias críticas, para la integración social desde los derechos humanos. Revista INVI, 25(69), 161-187. http://dx.doi.org/10.4067/S071883582010000200005

Barreto, M. Á. (2012). Cambios y continuidades en la política de vivienda argentina (2003-2007). Cuadernos de vivienda y urbanismo, 5(9), 12-30. Recuperado de https://goo.gl/MKRRHy.

Barrionuevo, L., Garbellotto, L., y Pasquale, M. F. (2011). Políticas habitacionales y de regularización dominial en Argentina: problemáticas en su aplicación a partir del estudio de caso de Villa La Tela. Ciudad de Córdoba, Argentina. 2009-2011. Cuaderno Urbano, 11(11), 123-148. Recuperado de https://goo.gl/vsnv8n.

Boccolini, S. M. (2017a). Producción privada de hábitat urbano en Córdoba, Argentina: condiciones internas y contextuales que organizan su desarrollo. Papeles de Geografía, O(63), 1-20. http://dx.doi.org/10.6018/geografia/2017/292751

Boccolini, S. M. (2017b). Regulação urbana em Córdoba. ¿Para uma cidade sustentável e inclusiva? Urbe [en prensa].

Boccolini, S. M. (2017c). Construcción sociodemográfica en Córdoba (Argentina): cambios de las estructuras sociales en el territorio, y su impacto en la demanda de hábitat urbano. Cadernos Metrópole [en prensa].
Capdevielle, J. (2014). Espacio urbano y desigualdades: las políticas públicas y privadas en la ciudad de Córdoba, Argentina (1990-2011). Cuadernos Geográficos, 53(2), 135-158. Recuperado de https://goo.gl/LmPq99.

Cardoso, M. M. (2013). Contraurbanización: ¿tendencia irreversible o la fase de un ciclo? La situación en América Latina. Geografia em Questão, 6(2), 108-134. Recuperado de https://goo.gl/6TeBaF.

Ciocca, S. (2015). Explorando nuevos paradigmas de políticas de hábitat. El plan ProCreAr (Conferencia magistral). Trabajo presentado en Jornadas UGYCAMBA 2015, Buenos Aires.

Coulomb, R. (2012). Las políticas habitacionales de los estados latinoamericanos. Seminario Taller Internacional Teorías sobre la ciudad. Buenos Aires: Universidad Nacional de General Sarmiento.

Cravino, A. (2009). Una historia sobre la transformación de la habitación popular en Buenos Aires (I). El debate sobre los conventillos. Café de las ciudades, LXXVI. Recuperado de https://goo.gl/JZ5jar.

Cravino, M. C. (2017). La cuestión de la vivienda en el Área Metropolitana de Buenos Aires (2003-2008). Ciudadanías. De ciudades, poblaciones, problemas y políticas, 1(1), 49-66

Cuenya, B. (1992). Políticas habitacionales en la crisis: el caso Argentina. Revista Vivienda, 3(3), 36-45. Recuperado de https://goo.gl/L46rF9.

Elorza, A. L. (2009). Estrategias de reproducción social de familias relocalizadas, entre la adaptación y el cambio. Conciencia Social, 9(12), 53-59.

Elorza, A. L. (2016). Segregación residencial socioeconómica y la política pública de vivienda social el caso de la ciudad de Córdoba (Argentina). Cuaderno Urbano, 20(20), 71-94. Recuperado de https://goo.gl//sCjY6

Esquivel Hernández, M. T., Pérez, E. M., y Cervantes Borja, J. (2005). La promoción privada y los grandes conjuntos habitacionales: nuevas modalidades de acceso a la vivienda. Scripta Nova. Revista Electrónica de Geografía y Ciencias Sociales, IX(194), 21. Recuperado de https://goo.gl/H1sHTz. 
Gargantini, D. M. (Ed.). (2014). Hábitat, acceso al suelo y financiamiento: experiencias alternativas de producción socio-habitacional. Córdoba: Asociación Vivienda Económica-AVE. Recuperado https://goo.gl/KbxKLB.

Instituto de Estadística y Registro de la Industria de la Construcción, IERIC. (2016). Informe de Coyuntura de la Construcción. Buenos Aires: IERIC. Recuperado de http://www.ieric.org.ar/publicaciones.asp.

Instituto Nacional de Estadísticas y Censos, INDEC. (2012). Censo Nacional de Población, Hogares y Viviendas 2010. Censo del Bicentenario Resultados definitivos, Serie $B$ No 2. Buenos Aires: Autor. Recuperado de https://goo.gl/PjyKWB.

Liernur, J. y Ballent, A. (2014). La casa y la multitud: vivienda política y cultura en la Argentina moderna. Buenos Aires: Fondo de Cultura Económica.

Luque Colombres, C. (1980). Orígenes históricos de la propiedad urbana de Córdoba (Siglos XVI y XVII). Córdoba: Dirección General de Publicaciones de la Universidad Nacional de Córdoba.

Marengo, M. C. y Elorza, A. L. (2016). Vivienda social en Córdoba, efectos en la segregación residencial y el crecimiento urbano (1991-2008). Revista INVI, 31(86), 119-144. $\quad$ https://doi.org/10.4067/S0718$\underline{83582016000100005}$

Ministerio de Planificación Federal, Inversión Pública y Servicios, MPFIPS. (2011). Plan Estratégico Territorial Avance II: Argentina Urbana. Buenos Aires: Letra Viva. Recuperado de https://goo.gl/8JX95Y.

Molinatti, F. (2013). Segregación residencial socioeconómica en la ciudad de Córdoba (Argentina): Tendencias y patrones espaciales. Revista INVI, 28(79), 61-94. https://doi.org/10.4067/S071883582013000300003
Monayar, V. (2011). Informalidad urbana y acceso al suelo. Acciones y efectos de la política habitacional en la ciudad de Córdoba-Argentina. Territorios, O(24), 113-130.

https://doi.org/10.12804/revistas.urosario.edu.co/ter ritorios/a.1596

Mora, M. y Araujo, M. (2002). La estructura social de la Argentina: Evidencias y conjeturas acerca de la estratificación actual. Santiago de Chile: Naciones Unidas.

Peralta, C. (2006). Demanda habitacional y políticas públicas en Córdoba. Trabajo presentado en el Primer Seminario Iberoamericano de Ciencia y Tecnología para el Hábitat Popular, Córdoba: Nobuko.

Peralta, C. y Liborio, M. (2014). Redistribución poblacional en la ciudad de Córdoba entre los períodos intercensales 1991-2001/2001-2008. Evaluación de los procesos de dispersión, densificación, gentrificación y renovación. Revista de Vivienda y Ciudad, 0(1), 99-113. Recuperado de https://goo.gl/0paF9l.

Rodríguez, A. y Sugranyes, A. (2004). El problema de vivienda de los “con techo". EURE (Santiago), 30(91), 53-65. https://doi.org/10.4067/S025071612004009100004

Rolnik, R., Pereira, A. L. dos S., Moreira, F. A., Royer, L. de O., lacovini, R. F. G., Nisida, V. C., ... Rossi, L. G. A. (2015). O programa Minha Casa Minha Vida nas Regiões Metropolitanas de São Paulo e Campinas: Aspectos socioespaciais e segregação. Cadernos Metrópole, 17(33), 127-154. https://doi.org/10.1590/18863

Tecco, C. y Fernández, S. (2005). Políticas públicas y segregación residencial socioeconómica en la ciudad de Córdoba, Argentina. Trabajo presentado en VII Seminario Nacional de la Red de Centros Académicos para el Estudio de Gobiernos Locales, Buenos Aires. Recuperado de https://goo.gl/Z6K1X8.

Yujnovsky, O. (1984). Claves políticas del problema habitacional argentino 1955-1981. Buenos Aires: Grupo Editor Latinoamericano. 